\title{
Política educacional no ensino superior: reflexões sobre a contribuição da assistência estudantil da UFRPE
}

\author{
Educational policy in higher education: \\ reflections on the contribution of UFRPE student assistance \\ Política educacional en la enseñanza superior: \\ reflexiones sobre la contribución de la asistencia de estudiantes de la UFRPE \\ JULIANA CAVALCANTI MACEDO \\ ANA DE FÁTIMA PEREIRA DE SOUSA ABRANCHES
}

\begin{abstract}
Resumo: Esta pesquisa teve como principal objetivo analisar a política de assistência estudantil da UFRPE (Sede), a partir da percepção dos estudantes beneficiados. A investigação se baseou no método quali-quanti. Dessa forma, foram aplicados questionários e realizadas entrevistas com os estudantes assistidos. O estudo revelou que a maioria dos estudantes avalia como boa a política de assistência estudantil da UFRPE, assim como, afirma que a assistência estudantil contribui muito para a sua permanência na universidade. Contudo, também revela algumas situações que precisam ser reavaliadas e melhoradas.
\end{abstract}

Palavras-chave: Ensino Superior; Assistência Estudantil; Permanência.

\begin{abstract}
The main objective of this research was to analyze the understanding of the beneficiary students on the student assistance policy of UFRPE (headquarters). The research was based on the quali-quanti method. In this way, questionnaires were applied and interviews were conducted with the assisted students. The study revealed that the majority of the students evaluate as good the policy of student assistance of the UFRPE. It also affirms that the student assistance contributes a lot to their stay in the university. However, it also reveals some situations that need to be re-evaluated and improved.
\end{abstract}

Keywords: Higher Education; Student Assistance; Permanence.

Resumen: Esta investigación tuvo como principal objetivo analizar la política de asitencia de los estudiantes de la UFRPE (Sede), a partir de la percepción de los estudiantes beneficiados. La investigación se basó en el método cuali cuantitativo. De esta forma, se aplicaron cuestionarios y se realizaron entrevistas con los estudiantes asistidos. El estudio reveló que la mayoría de los estudiantes evalúa como buena la política de asistencia de estudiantes de la UFRPE, así como, afirma que la asistencia de estudiantes contribuye mucho a su permanencia en la universidad. Sin embargo, también revela algunas situaciones que necesitan ser reevaluadas y mejoradas.

Palabras clave: Enseñanza superior; Asistencia de Estudiantes; Permanencia. 


\section{INTRODUÇÃO}

A educação no Brasil é marcada por desafios e proposições pertinentes ao processo de transformação. Por sua vez, a educação superior tem como função essencial a formação de sujeitos autônomos, assim como, a construção de conhecimentos integrados à formação crítica e reflexiva. Além de constituir-se como um fator fundamental para o desenvolvimento econômico, social e político do país (DIAS SOBRINHO, 2005).

$\mathrm{Na}$ década de 1990, as transformações da educação superior brasileira resultaram em um crescente acesso ao ensino superior, com ênfase na expansão privada, em detrimento da pública. Iniciaram-se, com efeito, reformas educacionais com a finalidade não só de expansão do ensino, mas também, de adequação da educação pública às mudanças da lógica de regulação capitalista, no bojo de transformações profundas nas esferas da economia, das instituições sociais, culturais e políticas, bem como na natureza das relações entre essas diferentes esferas (KRAWCZYK; VIEIRA, 2006).

A partir do governo do presidente Luiz Inácio Lula da Silva em 2003, a política delineada envolve a democratização do acesso e garantia de permanência, qualidade social da educação e implantação do regime de colaboração e democratização da gestão, inclusão social e redução das desigualdades regionais. De acordo com as propostas desse governo, de democratização do acesso ao ensino superior, destacam-se o Programa de Apoio a Planos de Reestruturação e Expansão das Universidades Federais (Reuni) dentre outros programas. Além da retomada da discussão sobre as políticas de ação afirmativa, em especial a reserva de vagas, objetivando a sua transformação em lei.

Como consequência da expansão do acesso, deu-se a necessidade de propiciar condições de permanência até a conclusão dos estudos, para os alunos com dificuldades socioeconômicas. Em Sguissardi (2014), vamos encontrar o seguinte esclarecimento:

A expansão da ES, para ser democrática e não se tornar mera massificação, deve apoiar-se em pelo menos dois componentes: igualdade de condições de acesso, de escolha de cursos e carreiras a cursar, e de permanência com sucesso até a titulação (SGUISSARDI, 2014, p. 81).

Dessa forma, a inclusão das populações marginalizadas torna-se uma prioridade para as políticas públicas devido às grandes desigualdades econômicas e sociais em que se encontram as sociedades modernas. 
Nesse contexto, com o considerável aumento das vagas nas universidades públicas e no acesso ao ensino superior por parte da população historicamente excluída de toda uma dinâmica educacional, surge o reconhecimento de que tão somente o ingresso na universidade pública não é capaz de garantir a permanência dos estudantes menos favorecidos nas instituições de ensino superior (IES) do país (SILVA JR, SGUISSARDI, 2000).

$\mathrm{O}$ ingresso no ensino superior confronta o estudante com inúmeras exigências e desafios de natureza pessoal, social, econômica, acadêmica e institucional que vão exigir alterações no seu padrão de comportamento. $O$ sucesso nessa etapa e, consequente, a adaptação do estudante ao ensino superior, depende não só de fatores meramente acadêmicos, como também, fatores contextuais, interpessoais e pessoais. Reconhece-se, então, a necessidade de criar condições, para a permanência desses estudantes na universidade, que possam refletir, também, na qualidade do ensino superior.

Dessa forma, com o objetivo de reduzir a desigualdade presente nas IES públicas foi instituído o Programa Nacional de Assistência Estudantil (Pnaes), pela Portaria Normativa do Ministério da Educação (MEC) n³9/2007, e regulamentado pelo Decreto ${ }^{\circ} 7.234 / 2010$ no governo do presidente Luis Inácio Lula da Silva, transformando o Pnaes em uma política de Estado (BRASIL, 2010). O Pnaes assume papel de centralidade para o Estado brasileiro na estratégia de combate às desigualdades sociais e regionais, por meio da democratização da Educação Superior (MEC, 2013), e define as diretrizes para as ações de assistência estudantil, direcionadas aos alunos em vulnerabilidade socioeconômica, e vem sendo implementado pelas universidades brasileiras na tentativa de garantir condições justas de permanência ao estudante no ensino superior. De acordo com Dutra e Santos (2017):

\begin{abstract}
À medida que se amplia o acesso de discentes advindos de escolas públicas e considerados em situação de vulnerabilidade socioeconômica, faz-se necessária a implementação de políticas que possibilitem a permanência desses universitários, entendendo-se o acesso e a permanência como partes indissociáveis de um processo contínuo (DUTRA e SANTOS, 2017, p.163).
\end{abstract}

A Universidade Federal Rural de Pernambuco (UFRPE) criou por meio da resolução $n^{\circ}$ 185/2006, com alteração pelas resoluções n ${ }^{\circ}$ 080/2016 e n ${ }^{\circ}$ 007/2019 do Conselho Universitário, a Pró-Reitoria de Gestão Estudantil e Inclusão (Progesti), com a missão de: 
contribuir para a permanência de estudantes de vulnerabilidade socioeconômica matriculados em curso de graduação presencial da UFRPE, como também incentivar, apoiar, orientar e acompanhar, de forma articulada com as demais Pró-Reitorias, Departamentos Acadêmicos, Departamentos Administrativos e Órgãos Suplementares, o estudante, em suas múltiplas demandas, no decorrer de sua trajetória acadêmica (PROGESTI, 2017).

Assim, o presente artigo apresenta uma pesquisa que teve por objetivo analisar a política de assistência estudantil da UFRPE Sede (Campus Dois Irmãos), a partir da percepção dos estudantes beneficiados. Os objetivos específicos foram: caracterizar a política de assistência estudantil da UFRPE Sede (Campus Dois Irmãos) e os estudantes que a acessam; analisar os significados e a importância atribuídos à política de assistência estudantil da UFRPE Sede (Campus Dois Irmãos) pelos estudantes beneficiados. Portanto, este estudo torna-se relevante pela possibilidade de contribuir para a reflexão e melhoria das políticas públicas de educação superior no Brasil.

\section{POLÍTICA PÚBLICA DE EDUCAÇÃO SUPERIOR E ASSISTÊNCIA ESTUDANTIL}

Segundo Saravia (2007), as políticas públicas constituem um fluxo de decisões públicas, voltadas para manter o equilíbrio social ou a introduzir desequilíbrios propostos para transformar determinada realidade. Dye (1984), por sua vez, sublinha que a política pública é algo que o governo escolhe ou não ofertar às sociedades. Souza vai mais além, e acrescenta a esse conceito a noção de como as políticas públicas são formuladas pelos governos. Em suas palavras, política pública significa um:

\footnotetext{
Campo do conhecimento que busca, ao mesmo tempo, "colocar o governo em ação" e/ou analisar essa ação (variável independente) e, quando necessário, propor mudanças no rumo ou curso dessas ações e ou entender por que o como as ações tomaram certo rumo em lugar de outro (variável dependente). Em outras palavras, o processo de formulação de política pública é aquele através do qual os governos traduzem seus propósitos em programas e ações, que produzirão resultados ou as mudanças desejadas no mundo real (SOUZA, 2003, p. 13).
}

Nessa perspectiva, Azevedo (1997) ressalta que as políticas são fruto da ação humana e, portanto, dependem do próprio sistema de representações sociais. São os diferentes atores sociais que entram em embates com os criadores de política, com suas concepções e apoio a algum tipo de definição do social da realidade. 
$\mathrm{O}$ acesso às universidades públicas foi por muito tempo de uso privilegiado das elites do país. Para Chauí (2001, p. 35), a universidade é uma instituição social que exprime de modo determinado a sociedade de que é e faz parte. A autora também argumenta que a universidade apresenta uma necessidade de transformação constante para adequar-se às diversas exigências sociais, motivo pelo qual vive suas crises.

De acordo com Machado (2013, p. 16) a educação superior precisa ser compreendida ainda enquanto uma "expressão da questão social", cuja desigualdade de acesso, permanência e qualidade reside no fato de serem produzidas e reproduzidas historicamente, a partir das condições econômicas, políticas e sociais impostas pelo capital. Nesse sentido, as políticas de ações afirmativas surgem com o objetivo de oferecer acesso democrático à educação, permitindo que pessoas de camadas mais pobres possam alcançar o seu direito ao ensino superior. Seu propósito é de fazer um resgate de direitos historicamente negados, como o direito à educação. Nesse sentido, Bergman (1996) entende de maneira ampla que:

Ação afirmativa é planejar e atuar no sentido de promover a representação de certos tipos de pessoas, aquelas pertencentes a grupos que têm sido subordinados ou excluídos em determinados empregos ou escolas. (BERGMAN, 1996, p. 7).

Todavia, entende-se que apenas o acesso ao ensino superior não é suficiente, torna-se necessária a criação de medidas que ofereçam aos estudantes, condições de permanência até a conclusão dos estudos. De acordo com Paula (2009):

O acesso ao ensino superior deve vir acompanhado de medidas efetivas que garantam a permanência dos estudantes nas universidades. Isso requer investimento considerável em assistência estudantil e depende do fortalecimento da educação pública em todos os níveis, fundamental, médio e superior, assim como de reformas sociais profundas que conduzam a uma melhor distribuição de renda, rompendo com a aviltante desigualdade e a crônica injustiça social existentes no Brasil (PAULA, 2009, p. 19).

Nesse contexto, o Pnaes, em vigor desde o ano de 2008, tem como intuito oferecer subsídios para que aqueles alunos com baixa renda consigam manter-se nos seus cursos de graduação. Tal medida visa diminuir a desigualdade social e possibilitar a democratização do acesso e da permanência dos estudantes no ensino superior federal. Segundo o Programa, isso será feito por meio de 
auxílio à moradia estudantil, alimentação, transporte, assistência à saúde, inclusão digital e atividades de cultura, esportes, creche e apoio pedagógico. Nesse sentido, pode-se afirmar que:

A promulgação do Programa Nacional de Assistência Estudantil (PNAES) em 12 de dezembro de 2007 representa um marco histórico e de importância fundamental para a questão da assistência estudantil. Essa conquista foi fruto de esforços coletivos de dirigentes, docentes e discentes e representou a consolidação de uma luta histórica em torno da garantia da assistência estudantil enquanto um direito social voltado para a igualdade de oportunidades aos estudantes do ensino superior público (VASCONCELOS, 2009, p. 608).

Dentro dessa perspectiva, Dutra e Santos (2017) constatam que no segundo mandato do presidente Luiz Inácio Lula da Silva:

A aprovação do Plano Nacional de Assistência Estudantil que culminou na instituição do Pnaes, em 2007, foi favorecida pela instituição, no mesmo ano, do Decreto no 6.096, de 24 de abril de 2007 (BRASIL, 2007), que cria o Programa de Apoio a Planos de Reestruturação e Expansão das Universidades Federais (Reuni). Esse, em seu artigo $1^{\circ}$, afirma que tem "o objetivo de criar condições para a ampliação do acesso e permanência na educação superior, no nível de graduação, pelo melhor aproveitamento da estrutura física e de recursos humanos existentes nas universidades federais". Em suas diretrizes, no artigo $2^{\circ}$, item V, estabelece a necessidade de "ampliação de políticas de inclusão e de assistência estudantil” (DUTRA E SANTOS, 2017, p.156).

Nesse novo cenário, as instituições a ele vinculadas passaram a acolher e continuam acolhendo sujeitos de diversificadas origens socioculturais, com consequente impacto em políticas educacionais (VASCONCELOS; GOMES, 2016).

NoâmbitodapolíticadeassistênciaestudantildaUFRPE,sãodesenvolvidos programas e ações com o objetivo de ampliar o acesso e a permanência no ensino superior por meio do atendimento aos estudantes em situação de vulnerabilidade socioeconômica. São oferecidos programas nas modalidades de apoio ao discente, apoio à gestante, apoio ao ingressante, residência e promoção de esportes. Os estudantes beneficiados pela assistência estudantil devem atender aos critérios estabelecidos pelo Pnaes, estar regularmente matriculados no semestre vigente em curso de graduação, concluir o curso dentro do prazo estabelecido pelas normas da UFRPE, estar em situação de vulnerabilidade socioeconômica - que significa possuir renda familiar de até um salário mínimo e meio - além de atender às exigências específicas de cada programa. A seleção desses estudantes é realizada por assistentes sociais que desenvolvem a análise socioeconômica por meio da comprovação da documentação e entrevista social, levando em consideração 
fatores como: renda familiar bruta mensal, número de pessoas do grupo familiar, despesas com moradia e transporte, doenças do grupo familiar, bens patrimoniais do grupo familiar, além de outras condições observadas em conformidade com a política de Assistência Social. De acordo com Back (2017, p. 79), "a situação de vulnerabilidade socioeconômica não se reduz à renda, mas a um conjunto de situações que se expressa pela ausência de direitos, falta de oportunidades, acesso às políticas sociais e outros fatores".

De acordo com os dados do relatório de gestão 2016 da UFRPE, o campus Sede da UFRPE, lócus desta pesquisa, atende a um quantitativo de 805 estudantes beneficiados no mês de junho de 2017. Todos esses estudantes estão em situação de vulnerabilidade socioeconômica.

\section{METODOLOGIA}

Do ponto de vista metodológico, a investigação se baseou no método quanti-quali. A escolha por essa estratégia metodológica deve-se ao fato de que "combinar técnicas de análise quantitativa com técnicas de análise qualitativa proporciona maior nível de credibilidade e validade aos resultados da pesquisa, evitando-se, assim, o reducionismo por uma só opção de análise" (OLIVEIRA, 2012, p. 39). Além disso, como destaca Creswell (2010), a combinação de dados dos tipos qualitativo e quantitativo pode ocorrer em distintos estágios de uma pesquisa: na coleta, na análise, na interpretação dos dados, ou nas três fases.

A pesquisa foi realizada por meio de questionário e entrevista. $\mathrm{O}$ questionário, composto por 24 (vinte e quatro) questões fechadas e 1 (uma) aberta, foi enviado por e-mail e direcionado aos 364 estudantes que possuíam cadastro com e-mail atualizado no banco de dados da Progesti/UFRPE; o restante ou não possuía os dados ou os dados estavam desatualizados. Obtevese um total de 82 questionários respondidos. A atividade consistiu em colher informações da população beneficiada, como dados gerais, opiniões ou respostas a perguntas formuladas sobre os indicadores os quais se pretendeu estudar. Quanto à entrevista, se caracterizou de forma semiestruturada com os estudantes beneficiados pela política de assistência estudantil da UFRPE. Para isso, optouse em delimitar o número de entrevistados a partir do tempo do ingresso do estudante na referida política. Desse modo, as entrevistas foram desenvolvidas com estudantes beneficiados por cada um dos quatro programas oferecidos pela Progesti (apoio ao discente, apoio à gestante, residência e promoção de esportes). Portanto, foram entrevistados dois estudantes de cada programa de acordo com o 
maior e o menor tempo de ingresso no programa, totalizando oito discentes. Nas entrevistas foram desenvolvidas pautas e tópicos, onde o informante discorreu livremente sobre as diversas temáticas apresentadas.

Por meio das respostas obtidas no questionário e entrevistas foram desenvolvidos gráficos e tabelas que apresentam os dados da pesquisa. $\mathrm{Na}$ análise desses dados, pretendeu-se promover uma interação dessas informações na busca de uma melhor compreensão do objeto estudado, tendo como técnica a análise de conteúdo. Como referenda Bardin, a análise de conteúdo configura-se como um:

Conjunto de técnicas de análise das comunicações visando obter, por procedimentos sistemáticos e objetivos de descrição do conteúdo das mensagens, indicadores (quantitativos ou não) que permitem a inferência de conhecimentos relativos às condições de produção/recepção (variáveis inferidas) destas mensagens (BARDIN, 1979, p. 42).

A partir da análise dos dados coletados, discutiu-se sobre o entendimento dos estudantes beneficiados sobre a assistência estudantil da UFRPE.

\section{RESULTADOS E DISCUSSÕES}

\section{CARACTERIZAÇÃO DOS ESTUDANTES BENEFICIADOS PELA ASSISTÊNCIA ESTUDANTIL DA UFRPE}

A primeira parte dos resultados desta pesquisa se refere aos dados obtidos através do questionário aplicado aos estudantes beneficiados pela política de assistência estudantil da UFRPE. Acerca do perfil dos estudantes que responderam ao questionário, foram levantadas informações relevantes que contribuíram para a análise dos dados. O primeiro eixo das questões teve como objetivo caracterizar os estudantes beneficiados, identificando o seu perfil.

Dos estudantes beneficiados pela assistência estudantil da UFRPE que responderam ao questionário, 53,66\% são do sexo feminino. Esses dados estão em conformidade com os dados gerais sobre o ensino superior no país, desenvolvidos pelo Instituto Nacional de Estudos e Pesquisas Educacionais Anísio Teixeira (Inep). Segundo o Inep (2019), o número de ingressantes mulheres na educação superior no ano de 2017 é de 55\%.

Nessa perspectiva, Leta (2003) considera que a partir da década de 1980, com a expansão de instituições de ensino superior, tanto pública quanto privada, aconteceu o que a autora denominou de evolução do número de mulheres matriculadas no ensino superior. Para esta autora, "é evidente a mudança na 
universidade brasileira no que diz respeito à frequência de mulheres: diferente de algumas poucas décadas atrás, elas hoje são a maioria em boa parte dos cursos de graduação do país" (LETA, 2003, p. 274).

Os estudantes, em sua maioria, possuem estado civil como solteiro, alcançando o percentual de $81,71 \%$. Esse alto percentual pode ser justificado pelo número elevado de estudantes com faixa etária entre 18 a 21 anos que soma $46,34 \%$ do total de estudantes da pesquisa. Quando cruzados esses dados, a pesquisa aponta que $41,46 \%$ dos estudantes com 18 a 21 anos são solteiros.

Segundo os dados da pesquisa do ano de 2015, do Instituto Brasileiro de Geografia e Estatística (IBGE, 2017), do total de estudantes na faixa entre 18 e 24 anos, parcela de 32,9\% frequentavam o Ensino Superior em 2004. Em 2014, dos estudantes dessa mesma faixa etária, 58,5\% estavam na faculdade. É um salto de mais de 30 pontos percentuais que representam um dado significativo e mostra que há uma forte tendência de democratização no acesso ao ensino superior no contexto de expansão e reestruturação do Ensino Superior, ocorrido no Brasil nos anos 2000. Em contrapartida, o último Censo da Educação Superior, divulgado no segundo semestre de 2017 pelo Inep (2017), apresenta uma diminuição no crescimento das matrículas no ensino superior se comparado aos últimos anos, porém essa diminuição se deu na rede privada, já na rede pública, percebe-se um aumento nesse número como podemos observar na tabela 1 abaixo.

\section{Tabela 1 - Número total de matrículas no ensino superior no Brasil} (2012 a 2016)

\begin{tabular}{|c|c|c|c|}
\hline ANO & Pública & Privada & TOTAL \\
\hline 2012 & 1.897 .376 & 5.140 .312 & 7.037 .688 \\
\hline 2013 & 1.932 .527 & 5.373 .450 & 7.305 .977 \\
\hline 2014 & 1.961 .002 & 5.867 .011 & 7.828 .013 \\
\hline 2015 & 1.952 .145 & 6.075 .152 & 8.027 .297 \\
\hline 2016 & 1.990 .078 & 6.058 .623 & 8.048 .701 \\
\hline
\end{tabular}

Fonte: Macedo (2017). Elaborada a partir dos dados do MEC/Inep (2017)

Até o ano de 2010, a predominância das matrículas no ensino superior era do setor privado. Entretanto, essa queda do número de matrícula observada em 2016 pode ter sido consequência da crise econômica e desemprego gerados no atual contexto socioeconômico e político enfrentado no país, causando impactos nesses resultados.

Em relação aos estudantes atendidos pela assistência estudantil, observa-se que os cursos que apresentaram maior quantidade de estudantes foram: Agronomia, Licenciatura Plena em Ciências Biológicas e Bacharelado em 
Ciências Biológicas. Os cursos que apresentaram menor quantidade de discentes foram: Bacharelado em Ciências Econômicas e Bacharelado em Sistemas de Informação. Acredita-se que essa baixa quantidade se deva ao fato de esses cursos serem relativamente novos na UFRPE. Quanto à escolha do curso superior, Nogueira (2007) esclarece que as pesquisas sobre o assunto vêm apontando que a distribuição dos indivíduos nos cursos superiores está estatisticamente ligada às suas características sociais, perfil acadêmico, etnia, sexo e idade. E também que existe um processo de auto seleção complexo na escolha do curso superior.

No que diz respeito à forma de ingresso, $91,46 \%$ dos estudantes pesquisados ingressaram na universidade pelo Exame Nacional do Ensino Médio (ENEM). Atualmente, o ENEM é a principal forma de ingresso no ensino superior, principalmente a partir de 2009, quando o MEC criou o Sisu oferecendo a possibilidade dos estudantes fazerem suas opções de inscrições de acordo com as vagas ofertadas nas universidades participantes desse sistema. Quanto ao tipo de escola em que o estudante realizou o ensino médio, verificou-se que 85,37\% cursaram o ensino médio em escola pública.

Quanto à cor e à etnia, 40,24\% dos estudantes declaram-se pardos, $30,49 \%$ pretos, $24,39 \%$ brancos, $2,4 \%$ amarelos, $1,2 \%$ indígenas e $1,2 \%$ nenhuma das respostas. O Censo do Ensino Superior, elaborado pelo Instituto Nacional de Estudos e Pesquisas Educacionais Anísio Teixeira (Inep) evidencia o aumento do número de matrículas de estudantes negros em cursos de graduação. Em 2011, do total de 8 milhões de matrículas, 11\% foram feitas por alunos pretos ou pardos. Em 2016, ano do último Censo, o percentual de negros matriculados subiu para 30\%. Apesar da grande diferença percentual, nota-se que o aumento da população negra na universidade foi mais significativo nesse período. Um dos fatores que pode explicar esse aumento se deve à adoção de políticas de ação afirmativa nos últimos anos, objetivando a diminuição da desigualdade social entre brancos, negros e indígenas. Quanto a essa questão, a Andifes está iniciando em 2018, a quinta edição da Pesquisa do Perfil Socioeconômico dos Estudantes das Universidades Federais. Como discutido anteriormente na seção destinada à política pública de assistência estudantil, esses estudos vêm apresentando uma significativa mudança no perfil dos estudantes de graduação das universidades públicas no Brasil, principalmente, a partir da adoção do ENEM como forma de acesso e da implementação da Lei 12.711/2012, chamada Lei de Cotas (BRASIL, 2012). Os dados têm revelado que negros e pardos juntos correspondem a $47,5 \%$ do total de estudantes das instituições brasileiras de ensino superior público, e que dois terços desses estudantes são oriundos de famílias com renda mensal de até um salário mínimo e meio (ANDIFES, 2018). 
A maioria dos estudantes pesquisados, 60,98\%, possui renda mensal da família de até 1 salário mínimo, estando abaixo do limite estipulado pelo PNAES que é de um salário mínimo e meio. Seguido de 32,93\% com renda de 2 salários mínimos, 3,7\% tem 3 salários e 2,4\% têm 4 salários mínimos. Segundo o Departamento Intersindical de Estatística e Estudos Socioeconômicos (DIEESE), o salário mínimo necessário para atender às necessidades de uma família com moradia, alimentação, educação, saúde, lazer, vestuário, higiene, transporte e previdência social, como prevê a Constituição Federal de 1988, sendo essa família composta por dois adultos e duas crianças, deveria ser, no mês de abril de 2017, de $R$ \$ 3.899,66, valor 4,07 vezes maior do que o salário em vigor de $R$ \$937,00 para dar conta das necessidades básicas de uma familia (DIEESE, 2017). No gráfico 1 abaixo, é possível verificar a relação entre raça e renda nos resultados da pesquisa realizada na assistência estudantil da UFRPE.

\section{Gráfico 1 - Relação entre raça e renda dos estudantes da assistência estudantil da UFRPE}

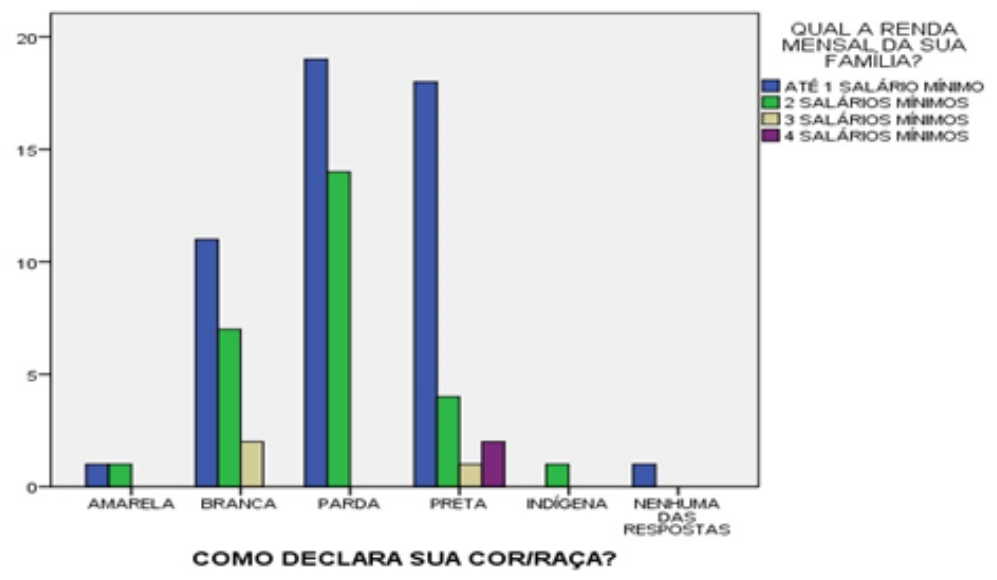

Fonte: Macedo (2017).

De acordo com o cruzamento das informações expostas no gráfico 1 acima, é possível perceber que negros e pardos com renda familiar de até um salário mínimo, aparecem em maior quantidade nos resultados da pesquisa. De acordo com Gentili (2009), "um pouco mais de 200 milhões de latino-americanos são pobres e indigentes e, entre os pobres e indigentes, os que sofrem essa condição de forma mais intensa são os negros e indígenas" (GENTILI, 2009, p. 1066). Dessa forma, é possível perceber que a maioria dos pesquisados vive com uma renda muito abaixo do salário necessário para o atendimento das suas necessidades básicas, inclusive, abaixo também do critério de renda estipulado 
pelo PNAES. Portanto, é um cenário que repercute no contexto educacional, pois "toda situação de pobreza estrutural ou de intensificação desta, inevitavelmente, exercerá impacto sobre o sistema escolar, questionando, interferindo e fragilizando as condições para o exercício do direito à educação" (GENTILI, 2009, p. 1065).

Quanto aos programas, a maioria dos estudantes, $54,9 \%$, é beneficiada pelo programa de Apoio ao Discente (modalidade transporte). Seguidos de 26,8\% do programa de Apoio ao Discente (modalidade apoio acadêmico) e 18,3\% do programa de Residência Universitária. O programa de Apoio à Gestante não obteve representatividade nesta pesquisa. Justifica-se a maior quantidade de estudantes no programa de Apoio ao Discente (modalidade transporte), devido à sua elevada oferta de vagas e menor valor do auxílio em comparação aos outros programas.

Quanto ao tempo que faz parte dos programas da assistência estudantil, a maioria dos pesquisados com 36,6\% está no programa entre 7 a 12 meses, seguido de $22 \%$ que fazem parte entre 13 a 18 meses. Somando os percentuais acima dos 13 meses, percebe-se que 57,3\% a maioria dos estudantes pesquisados, está na assistência estudantil há pelo menos mais de um ano. Portanto, são pessoas que têm uma vivência razoável dentro da política estudada como mostra a tabela 2 abaixo.

\section{Tabela 2 - Tempo no programa de assistência estudantil da UFRPE}

\begin{tabular}{|l|c|}
\hline Tempo que faz parte do programa & $\%$ \\
\hline Até 6 meses & 6,1 \\
\hline 7 a 12 meses & 36,6 \\
\hline 13 a 18 meses & 22,0 \\
\hline 19 a 24 meses & 11,0 \\
\hline 25 a 30 meses & 7,3 \\
\hline 31 a 36 meses & 8,5 \\
\hline Mais que 37 meses & 8,5 \\
\hline Total & 100,0 \\
\hline
\end{tabular}

Fonte: Macedo (2017).

\section{AVALIAÇÃO DOS ESTUDANTES BENEFICIADOS SOBRE A POLÍTICA DE ASSISTÊNCIA ESTUDANTIL DA UFRPE}

Com relação ao segundo eixo das questões, seu objetivo consistiu em analisar a avaliação dos estudantes beneficiados sobre a política de assistência estudantil e sua influência na permanência desse estudante na universidade, assim 
como o atendimento das suas necessidades acadêmicas. No que diz respeito à contribuição da assistência estudantil para a permanência do estudante na universidade, $84,1 \%$ dos pesquisados afirmaram que a assistência estudantil da UFRPE contribui muito para a sua permanência na universidade. Esse dado revela a importância da política para a permanência da maioria dos estudantes com baixa renda.

Quanto à avaliação da Política de Assistência Estudantil da UFRPE pelos estudantes pesquisados, a maioria $47,6 \%$ respondeu que considera a política boa, seguido de $28 \%$ muito boa e $20,7 \%$ aceitável. Esse resultado evidencia que a grande maioria avalia positivamente a política.

Quando perguntado sobre como concluiria o curso, caso perdesse o benefício da assistência estudantil, 48,8\% dos pesquisados responderam que desistiriam do curso, seguido de $41,5 \%$ que buscariam outra fonte de renda e $24,4 \%$ que buscariam ajuda da família. Esse dado revela que o benefício é determinante para a permanência desses estudantes, e também, corrobora a questão referente à contribuição para a permanência, revelando a importância da política para a permanência do aluno na universidade e consequente conclusão do curso.

A questão relativa à prioridade no uso da bolsa/auxílio revela que a maioria $89,9 \%$ utiliza o valor do benefício com transporte, seguido de $67,1 \%$ com alimentação, 56,1\% com despesas de formação universitária, 36,6\% com higiene pessoal e $28,8 \%$ com ajuda familiar. Esses dados mostram que alguns estudantes utilizam o benefício para suprir outras necessidades, revelando além das dificuldades enfrentadas no cotidiano acadêmico, dificuldades vivenciadas no cotidiano familiar. Pode-se dizer que a realidade social experimentada pelos estudantes da UFRPE é resultado do contexto socioeconômico e político apresentado atualmente pelos trabalhadores no Brasil, e que exige, para seu enfrentamento, um investimento em políticas de trabalho e renda. Podem-se observar na tabela 3, abaixo, as prioridades dos beneficiados no uso do valor da bolsa/auxílio, levando em consideração que essa questão é estimulada e de múltiplas respostas gerando percentuais que podem ultrapassar os $100 \%$. 


\section{Tabela 3 - Prioridade no uso do valor da bolsa/auxílio}

\begin{tabular}{|l|c|}
\hline Qual (is) a(s) sua (s) prioridade(s) no uso do valor da bolsa/auxílio que você recebe? & $\%$ \\
\hline Alimentação & 67,1 \\
\hline Moradia & 9,8 \\
\hline Transporte & 89,9 \\
\hline Higiene pessoal & 36,6 \\
\hline Ajuda familiar & 28,8 \\
\hline Gastos relacionados à formação universitária & 56,1 \\
\hline Saúde & 1,2 \\
\hline
\end{tabular}

Fonte: Macedo (2017).

Quando questionado se possuía outra fonte de renda, 61\% afirmaram não ter outra fonte de renda, seguido de 18,3\% com estágio remunerado e 11\% com ajuda da família. Portanto, a maioria dos estudantes pesquisados possui apenas o benefício da assistência estudantil para continuar e concluir os estudos na universidade.

$\mathrm{Na}$ questão que pergunta se o benefício é suficiente para suprir as necessidades acadêmicas dos estudantes, 43,9\% responderam "às vezes", seguido de 32,9\% que responderam "nunca" e 23,2\% que responderam "geralmente". É possível observar que a política contribui para a permanência e conclusão dos estudos na universidade, mas possui fragilidades, visto que se apresenta como insuficiente no que diz respeito ao valor dos benefícios. $\mathrm{Na}$ tabela 4, abaixo, pode-se observar a evolução do reajuste dos benefícios da assistência estudantil da UFRPE.

Tabela 4 - Reajuste dos benefícios da assistência estudantil da UFRPE no período de 2012 a 2016

\begin{tabular}{|l|c|c|c|c|c|}
\hline \multirow{2}{*}{ BOLSAS/AUXíLIOS } & \multicolumn{5}{c|}{ PERIOODO/VALORES (R\$) } \\
\cline { 2 - 6 } & $\mathbf{2 0 1 2}$ & $\mathbf{2 0 1 3}$ & $\mathbf{2 0 1 4}$ & $\mathbf{2 0 1 5}$ & $\mathbf{2 0 1 6}$ \\
\hline Apoio acadêmico & 290,00 & 290,00 & 320,00 & 320,00 & 345,00 \\
\hline Bolsa de Informática & 290,00 & 290,00 & 320,00 & 320,00 & -- \\
\hline Bolsa Coral & 290,00 & 290,00 & 320,00 & 320,00 & 345,00 \\
\hline Auxílio Alimentação & 85,00 & 85,00 & 105,00 & 105,00 & 120,00 \\
\hline Auxílio Creche & -- & -- & -- & 320,00 & 345,00 \\
\hline Auxílio Creche 50\% & -- & -- & -- & 160,00 & 172,50 \\
\hline Auxílio Transporte & 60,00 & 60,00 & 75,00 & 75,00 & 90,00 \\
\hline Auxílio Manutenção & 345,00 & 345,00 & 380,00 & 380,00 & 410,00 \\
\hline Auxílio Moradia & 280,00 & 280,00 & 310,00 & 310,00 & 335,00 \\
\hline
\end{tabular}

Fonte: Relatório de Gestão da Progesti 2016.

929 - RBPAE - v. 35, n. 3, p. 916 - 940, set./dez. 2019 
Diante da tabela acima, pode-se verificar que no período compreendido entre 2012 a 2013, não houve aumento nos benefícios. Em 2014, houve um aumento entre 15 reais a 35 reais. E em 2016, constata-se um aumento entre 15 reais a 30 reais. Considera-se irrelevante o aumento do valor benefício, diante das necessidades dos estudantes. É importante destacar que a bolsa de informática era uma ação que tinha como público estudantes selecionados por professores para exercer contrapartida nos laboratórios de informática da universidade e existiu até o ano de 2016. E a bolsa coral era uma ação de cultura destinada aos estudantes com aptidão musical, independente do perfil socioeconômico. Tanto a bolsa informática como a bolsa coral não previam o critério socioeconômico nas seleções e eram pagas com o recurso Pnaes até o ano de 2016, quando a bolsa informática foi extinta, e a bolsa coral passou a ser concedida através de editais de seleção, apresentando o perfil socioeconômico como um dos critérios de seleção. $\mathrm{Na}$ tabela 5 abaixo é possível perceber a progressão dos recursos do Pnaes que foram destinados a UFRPE entre 2012 a 2017.

\section{Tabela 5 - Progressão dos Recursos do PNAES destinados à UFRPE para Assistência ao Estudante do Ensino Superior}

\begin{tabular}{|c|c|}
\hline ANO & VALOR \\
\hline 2012 & 6.073 .261 \\
\hline 2013 & 7.817 .636 \\
\hline 2014 & 9.991 .219 \\
\hline 2015 & 10.585 .081 \\
\hline 2016 & 11.671 .357 \\
\hline 2017 & 11.333 .921 \\
\hline
\end{tabular}

Fonte: Macedo (2017). Elaborado a partir dos dados das Leis Orçamentárias dos anos de 2012 a 2017.

A partir das informações expostas nas tabelas acima, é possível constatar um aumento significativo dos recursos destinados à assistência estudantil da UFRPE, porém verifica-se uma redução da taxa de crescimento no período compreendido entre 2016 e 2017. Vale lembrar que em 2016, houve a aprovação da Emenda Constitucional $n^{\circ} 95$, que estabeleceu um regime fiscal que limita os gastos públicos por 20 anos, o que provavelmente resultará no retrocesso da garantia dos direitos sociais como educação, saúde, previdência e assistência social.

No que diz respeito às dificuldades na realização dos estudos, 59,8\% responderam que possuem dificuldades que interferem na vida acadêmica. Ao responder sobre essas dificuldades, $42,7 \%$ dos estudantes pesquisados atribuíram 
como obstáculo a dificuldade financeira, seguido de 25,6\% como dificuldades de aprendizagem, 23,2\% como metodologia do docente e 15,9\% como problema pessoal. Pode-se perceber que a questão financeira perpassa por todas as esferas e é crucial e determinante para um bom desempenho acadêmico. Na tabela 5, abaixo, é possível observar os dados referentes às dificuldades na realização dos estudos, levando em consideração que essa questão é estimulada e de múltiplas respostas, gerando percentuais que podem ultrapassar os $100 \%$.

\section{Tabela 6 - Dificuldades na realização dos estudos}

\begin{tabular}{|l|c|}
\hline Quais as suas dificuldades na realização dos seus estudos & $\%$ \\
\hline Saúde & 2,4 \\
\hline Problemas pessoais & 15,9 \\
\hline Relacionamento social/interpessoal & 6,1 \\
\hline Dificuldades financeiras & 42,7 \\
\hline Trabalho & 6,1 \\
\hline Metodologia docente & 23,2 \\
\hline Dificuldades de aprendizagem & 25,6 \\
\hline Outras & 3,6 \\
\hline
\end{tabular}

Fonte: Macedo (2017)

Quando questionados se a assistência estudantil desenvolve ações que ajudam nas suas dificuldades acadêmicas, $28 \%$ dos pesquisados responderam "geralmente", seguido de 24,4\% "às vezes", 20,7\%, "nunca", 15,9\%, "raramente" e $11 \%$, "sempre". Considera-se que parte significativa dos entrevistados entende que a assistência estudantil da UFRPE possui fragilidades no que tange o desenvolvimento de ações que auxiliem os estudantes no seu desenvolvimento acadêmico.

Em relação à questão aberta do questionário, referente às ações desenvolvidas pela assistência estudantil que ajudam nas dificuldades acadêmicas, 25 (vinte e cinco) estudantes responderam à questão. Dentre eles, 9 (nove) especificaram o Restaurante Universitário como ação; 8 (oito), o auxílio transporte; 7 (sete), a bolsa que recebem; 3 (três), o serviço de psicologia; 2 (dois), o serviço de pedagogia e 2 (dois), o acompanhamento psicossocial. Por meio desses dados, pode-se inferir que a maioria dos estudantes percebe a alimentação, o transporte e a renda como um apoio para o seu desenvolvimento acadêmico, antes até de ações de apoio acadêmico como o serviço de psicologia e pedagogia.

$\mathrm{Na}$ questão que diz respeito à opinião dos estudantes sobre promoção da igualdade social pela assistência estudantil, a maioria com 41,5\% concorda em parte que a assistência estudantil promove a igualdade social, seguido de 39\% 
que concordam, 7,3\% que discordam em parte dessa promoção, $6,1 \%$ indecisos e sem opinião e $6,1 \%$ que discordam. Por meio dos resultados, pode-se inferir que a política tem oportunizado a permanência, porém o estudante não tem se sentido inserido de forma integral e igualitária na universidade. Portanto, tornase necessário mais do que democratização, é preciso garantir a esse estudante o direito à igualdade. Para Cury,

A dialética entre o direito à igualdade e o direito à diferença na educação escolar como dever do Estado e direito do cidadão não é uma relação simples. De um lado, é preciso fazer a defesa da igualdade como princípio de cidadania, da modernidade e do republicanismo. A igualdade é o princípio tanto da nãodiscriminação quanto ela é o foco pelo qual homens lutaram para eliminar os privilégios de sangue, de etnia, de religião ou de crença. Ela ainda é o norte pelo qual as pessoas lutam para ir reduzindo as desigualdades e eliminando as diferenças discriminatórias. Mas isto não é fácil, já que a heterogeneidade é visível, é sensível e imediatamente perceptível, o que não ocorre com a igualdade. Logo, a relação entre a diferença e a heterogeneidade é mais direta e imediata do que a que se estabelece entre a igualdade e a diferença (CURY, 2002, p. 255).

Os dados referentes à questão de igualdade social revelam que a política parece não ter conseguido promover a igualdade social, mas tem abrandado as desigualdades sociais, pois a maioria dos estudantes beneficiados respondeu que a assistência estudantil promove em parte a igualdade social. A análise dos dados evidencia que, embora a assistência estudantil possa contribuir para minimizar a desigualdade social existente, não consegue tornar a igualdade concreta, nem eliminar as desigualdades. Entende-se que para que o estudante se sinta incluído, a universidade precisa oferecer condições para que esse discente possa acompanhar o processo acadêmico com sucesso, gerando também um sentimento de igualdade nos resultados de aprendizagem.

Dentro dessa perspectiva, Gentili (2009) esclarece que:

A inclusão é um processo democrático integral, que envolve a superação efetiva das condições políticas, econômicas, sociais e culturais que historicamente produzem a exclusão. Por esse motivo, indicadores de melhorias nas condições de acesso a um direito, assim como todo avanço na luta contra a alienação, segregação ou negação de oportunidades, embora sempre suponham grandes conquistas populares, podem não ser suficientes para consagrar o fim dos processos de exclusão historicamente produzidos e que condicionam ou negam esse direito. É apressado, portanto, considerar que um direito está consagrado simplesmente pela superação parcial das condições que o negavam no passado. Em outras palavras, a inclusão educacional é um processo que se constrói em oposição às forças e tendências que produziram e historicamente produzem a negação do direito à educação dos mais pobres e excluídos (GENTILI, 2009, p. 1063). 
Quanto à política, pode-se concluir que "não consegue romper a estrutura verticalizada e desigual da sociedade. Melhoram as condições de vida de milhares de jovens, e isso é altamente positivo, porém não alteram radicalmente o panorama social polarizado" (DIAS SOBRINHO, 2011, p. 148).

\section{CONDIÇÕES DE PERMANÊNCIA E CONCLUSÃO DO CURSO E NECESSIDADES ACADÊMICAS DOS ESTUDANTES BENEFICIADOS PELA ASSISTÊNCIA ESTUDANTIL DA UFRPE}

A segunda parte dos resultados desta pesquisa se refere aos dados obtidos através da entrevista realizada com os estudantes beneficiados pela política de assistência estudantil da UFRPE que tiveram seus nomes substituídos pela letra P (de pessoa) junto com o número de identificação da entrevista, ficando assim: P2, P4, P6, P7 e P8. Quanto à caracterização dos beneficiados, 4 (quatro) estudantes são do sexo feminino e 4 (quatro) do sexo masculino. Quanto ao curso dos discentes, 2 (dois) são de Economia Doméstica, 2 (dois) de Letras/ Espanhol, 1 (um) de Administração, 1 (um) de Licenciatura em Física, 1 (um) de Engenharia Florestal e 1 (um) de Ciências Sociais. Quanto à idade dos participantes, evidencia-se que elas variam de 19 a 25 anos, e três participantes possuem 29, 46 e 55 anos. Em relação ao tempo de permanência nos programas, critério selecionado para a escolha dos participantes da entrevista, percebe-se que 4 (quatro) estudantes fazem parte entre 8 meses a 1 ano, e 4 (quatro) alunos fazem parte entre 2 anos e 7 meses a 8 anos. A entrevista abordou como tema o entendimento dos estudantes acerca das condições de permanência e conclusão do curso e necessidades acadêmicas dos estudantes, revelando a contribuição da assistência estudantil, os pontos fortes e negativos. Este tema teve como objetivo avaliar as ações de assistência estudantil na permanência do estudante, oriundo do meio rural na universidade. A análise dos dados revelou que todos os estudantes afirmaram que a assistência estudantil é essencial para a sua permanência na universidade:

Se não fosse a Residência, eu não iria conseguir ficar no curso. Eu não teria condições de me manter aqui e não teria condições de estudar. Antes de entrar na Residência, eu tirei muitas notas baixas. Se não fosse a Residência, eu não continuaria no curso (P2).

Apesar de todos os percalços, a assistência estudantil foi fundamental, porque sem ela não existiria P4 se formando em Engenharia Florestal. Porque eu não tinha condições de ir e vir para cá, não tinha parente aqui para ficar. Nos primeiros dias que eu cheguei, até rodei com o colchão na cabeça e dormindo na casa de um e de outro (P4). 
Os extratos evidenciam a importância da assistência estudantil para a permanência dos entrevistados na universidade. Além disso, a maioria dos estudantes enfatizou que sem a assistência estudantil não continuaria o curso. Esses dados corroboram a importância dessa política para a permanência dos estudantes beneficiados. Outros relataram que precisariam de ajuda ou procurariam um trabalho. Faz-se um destaque para a fala de um entrevistado que afirma que a assistência permite o estudo com qualidade e dedicação:

Esse tipo de auxílio consegue me ajudar de forma que eu posso me dedicar ao curso. Permite que eu estude tarde e noite podendo almoçar e jantar aqui, que eu possa arcar com as xerox porque eu estou pagando seis disciplinas, então é muito mais textos. Hoje, eu consigo acompanhar melhor, ter uma grade de horário maior, me dedicar ao curso. Eu venho para cá de manhã e fico estudando, à tarde e à noite eu tenho aula. Então, eu consigo ter esse tipo de dedicação maior e qualidade melhor por causa dessa bolsa. Se não fosse pela bolsa, provavelmente não estaria com a quantidade de disciplinas que tenho hoje por conta das xerox, da alimentação, de tudo isso. Então, com certeza a bolsa auxilia completamente na minha estadia hoje no curso (P8).

Dessa forma, é possível perceber que muitos estudantes não concluiriam o curso, caso não recebessem a bolsa ou auxílio da Progesti. E muitos deles teriam que pedir auxílios ou trabalhar para continuar o curso, prejudicando assim a qualidade dos estudos.

Sobre o entendimento dos estudantes acerca das condições de permanência e conclusão do curso, eles foram questionados sobre os pontos fortes e fracos da assistência estudantil da UFRPE. A análise dos dados da pesquisa revelou que metade dos estudantes entrevistados identificou como ponto forte da assistência estudantil o apoio à permanência na universidade, conforme destaques a seguir:

A assistência estudantil me ajuda com as passagens. Apesar de ser pouco, é um instrumento que faz com que as pessoas continuem aqui. Teve gente que quando perdeu o benefício, não conseguiu ficar na universidade. A minha história é muito confortável diante de tantas histórias aqui de pessoas que não tem como vir para cá, não tem como se alimentar (P7).

Quando fui assinar o termo, vi pessoas que iam desistir da universidade pelas dificuldades, e por causa da bolsa, resolveram continuar. Então, vejo como ponto forte essa questão do apoio para que você não desista do seu curso (P8). 
Além do apoio à permanência, o acolhimento aos estudantes foi citado por dois entrevistados:

O ponto forte é todo o apoio que a gente recebe. A gente é bem acolhido, tem com quem conversar, é entendido (P6).

A Progesti está sempre aberta para receber o estudante. Quando eu entrei aqui, me falaram que se eu tivesse alguma dificuldade, que eu procurasse a Progesti, os psicólogos disponíveis. Então, essa abertura para os estudantes que recebem a bolsa, eu acho muito bom (P8).

Também, foram mencionados como pontos fortes da assistência estudantil da UFRPE pelos entrevistados: o apoio contra a evasão dos estudantes, o Restaurante Universitário, o programa de Residência Universitária, o cumprimento do pagamento das bolsas e a oferta de ônibus para viagens. Ainda em referência aos pontos fortes, pode-se destacar uma fala muito expressiva que revela a importância que a assistência estudantil tem para a vida de alguns estudantes:

O ponto forte que eu vejo está no fato de que os alunos realmente têm uma melhoria com esse recebimento da bolsa, uma melhoria no curso, no meio acadêmico. As pessoas parecem se dedicar mais para dar continuidade e manter a bolsa. Também tem uma melhoria de vida porque você pode almoçar, jantar e estudar aqui. Você tem acesso ao material do curso com a bolsa, que isso para mim é o principal (P8).

Com relação aos pontos fracos da assistência estudantil da UFRPE, esses se sobressaem em quantidade com relação aos pontos fortes, pois foram relatados muito mais pontos fracos do que fortes. Metade dos entrevistados destacou a falta de contato com os estudantes como ponto fraco da assistência estudantil, como é possível verificar no trecho destacado abaixo:

O ponto negativo seria a comunicação. Para dar um exemplo, os colchões que chegaram para residência estavam na Progesti há um tempão, e a gente estava lá sem os colchões há um tempão também. E não se pôde entregar por causa de tombamento. Sei que não compete à Progesti essa questão do tombamento, mas ela poderia tentar agilizar essas coisas e avisar para gente. Eu acho que a comunicação da Progesti com os residentes deveria ser melhor, porque é mais fácil a gente vir aqui se comunicar, do que a comunicação daqui chegar lá, avisos ou coisas desse tipo. Agora no período do recesso, a gente pediu o "De volta ao lar", que é uma ajuda de custo para você ir para a sua casa nas férias, e também, o auxílio alimentação porque você não tem o R.U nesse período. E nem saiu o auxílio, nem o "De volta ao lar". E a Pró-Reitoria nem se prontificou, não deu nenhuma notícia. Eu não passei tanto sufoco, porque já tinha feito a feira, dividindo com os meus amigos, mas quem estava precisando se ferrou (P2). 
Também foi citada pela metade dos entrevistados, a falta de divulgação da assistência estudantil na universidade:

É pouco divulgado. Tem gente que não sabe quem é o psicólogo, nem quem é a pedagoga, tem gente que não sabe nem quem é a coordenadora. Está faltando essa divulgação. Tem residente que não sabe quem é o pró-reitor, a secretária dele (P4).

Através dos fragmentos dos entrevistados, evidencia-se que os estudantes se sentem sozinhos e desinformados nas suas jornadas acadêmicas. Alguns deles se queixam de não serem contatados pela Pró-Reitoria e de se sentirem como um cadastro, um valor a mais. Também, pode-se verificar diante das falas dos estudantes, a falta de divulgação da assistência estudantil na universidade, o que significa uma grande falha, pois entende-se que todos têm direito à assistência estudantil, e muitos estudantes desconhecem a existência desse direito.

Dessa forma, pode-se concluir que os discentes da assistência estudantil consideram a política como essencial para a sua permanência na universidade diante da atual situação socioeconômica, entretanto, apontam mais fragilidades que contribuições.

\section{CONSIDERAÇÕES FINAIS}

O estudo revelou que a maioria dos estudantes avalia como boa a política de assistência estudantil da UFRPE, assim como afirma que a assistência estudantil contribui muito para a sua permanência na universidade. Contudo, também revela algumas situações que precisam ser reavaliadas e melhoradas. A renda familiar da maioria dos estudantes beneficiários da política está abaixo da estipulada pelo PNAES, o que demonstra que o perfil desses estudantes é de extrema vulnerabilidade socioeconômica e, por isso, justifica-se que a maioria das respostas dos estudantes pesquisados apresente o valor do benefício como insuficiente para as necessidades desses discentes, assim como aponte dificuldades financeiras como um entrave na realização dos estudos. Portanto, a questão financeira tem perpassado por todas as esferas sendo crucial para o bom desempenho desses estudantes.

A política tem se revelado determinante para permanência desses estudantes na universidade, contudo, uma parte significativa dos discentes pesquisados entende que a assistência estudantil possui fragilidades no que tange o desenvolvimento de ações que os auxiliem no seu desempenho acadêmico. 
A pesquisa apresenta também que os estudantes percebem a inclusão social pela assistência estudantil como parcial. Isso evidencia que a política parece ter conseguido abrandar as desigualdades sociais.

Dessa forma, é possível concluir que a política de assistência estudantil da UFRPE tem contribuído significativamente no que diz respeito à permanência do estudante na universidade, entretanto, as ações de permanência, desenvolvidas pela UFRPE, não têm sido suficientes para atender aos estudantes nas suas necessidades acadêmicas.

\section{REFERÊNCIAS}

ASSOCIAÇÃO NACIONAL DOS DIRIGENTES DE INSTITUIÇÕES FEDERAIS DE ENSINO SUPERIOR. Andifes realiza nova pesquisa sobre o perfil dos estudantes das Universidades Federais. Brasília, DF: Andifes, 2018. Disponível em: < http://www.andifes.org.br/andifes-realiza-nova-pesquisasobre-o-perfil-dos-estudantes-das-universidades-federais/>. Acesso em: 20 jan. 2018.

AZEVEDO, J. M. L. A educação como política pública. Campinas, SP: Autores Associados, 1997.

BACK, L. B. Política de assistência estudantil: interfaces com o reconhecimento das diferenças e a promoção da equidade. 2017. 145 f. Dissertação (Mestrado em Ciências Humanas) - Universidade Federal da Fronteira do Sul, Rio Grande do Sul.

BARDIN, L. Análise de conteúdo. Lisboa: Ed. 70, 1979.

BERGMANN, B. In defense of affirmative action. New York: BasicBooks, 1996.

BRASIL. Decreto no 7234 de 19 de julho de 2010. Dispõe sobre o Programa Nacional de Assistência Estudantil - PNAES. Brasília, DF, 2010.

. Lei $\mathrm{n}^{\circ} 12.711$, de 29 de agosto de 2012. Dispõe sobre o ingresso nas universidades federais e nas instituições federais de ensino técnico de nível médio e dá outras providências. Diário Oficial da União, 30 ago. 2012. 
. Ministério da Educação. Manual de gestão do programa de bolsa permanência. Brasília, DF: Ministério da Educação, 2013.

CHAUÍ, M. de S. Escritos sobre a universidade. São Paulo: UNESP, 2001.

CRESWELL, J. W. Projeto de pesquisa: métodos qualitativo, quantitativo e misto. 3. ed. Porto Alegre: Artmed, 2010.

CURY, C. R. J. Direito à educação: direito à igualdade, direito à diferença. Cadernos de Pesquisa, São Paulo, n. 116, p. 245-262, jul. 2002. Disponível em: http:// www.scielo.br/scielo.php?script $=$ sci_arttext\&pid=S0100-15742002000200010. Acesso em 17 nov. 2017.

DIAS SOBRINHO, J. Dilemas da educação superior no mundo globalizado: sociedade do conhecimento ou economia do conhecimento? São Paulo: Casa do Psicólogo, 2005.

DIEESE. Pesquisa nacional da Cesta Básica de Alimentos: Salário mínimo nominal e necessário. Disponível em: http://www.dieese.org.br/ analisecestabasica/salarioMinimo.html. Acesso em: 12 de julho de 2017.

DYE, T. D. Understanding public policy. Englewood Cliffs, N.J.: Prentice Hall. 1984.

DUTRA, N. G. dos R; SANTOS, M. de F. de S. Assistência Estudantil sob múltiplos olhares: a disputa de concepções. Ensaio: avaliação de políticas públicas educacionais. Rio de Janeiro, v.25, n.94, p.148-181, 2017.

GENTILI, P. O direito à educação e as dinâmicas de exclusão na América Latina. Educação e Sociedade, Campinas, v. 30, n. 109, p. 1059-1079, set./dez. 2009.

IBGE. Instituto Brasileiro de Geografia e Estatística. Síntese de Indicadores Sociais 2015. Disponível em: http://www.ibge.gov.br/home/estatistica/ populacao/condicaodevida/indicadoresminimos/sinteseindicsociais2015/ default.shtm. Acesso em: 12 de julho de 2017.

KRAWCZYK, N. R.; VIEIRA, V. L. Homogeneidade e heterogeneidade nos sistemas educacionais: Argentina, Brasil, Chile e México. Cadernos de Pesquisa, São Paulo, v. 36, n. 129, p. 673-704, dez. 2006. 
LETA, Jacqueline. As mulheres na ciência brasileira: crescimento, contrastes e um perfil de sucesso. Estudos Avançados, vol.17 ñ .49 São Paulo Sept./Dec. 2003. Disponível em: http://www.scielo.br/scielo. Acesso em: 20 dez. 2017.

MACEDO, J. C. Política Pública de Assistência Estudantil: uma análise a partir da percepção dos estudantes beneficiados da Universidade Federal Rural de Pernambuco. 2018. 117 f. Dissertação (Mestrado em Educação, Culturas e Identidades) - Universidade Federal Rural de Pernambuco e Fundação Joaquim Nabuco, Pernambuco.

MACHADO, M. P. O pacto neodesenvolvimentista e as políticas de expansão da educação superior no Brasil de 2003 a 2013. 2013. 220 f. Tese (Doutorado em Educação) - Universidade Federal do Paraná, Curitiba, 2013.

NOGUEIRA, C. M. M. O processo de escolha do curso superior: análise sociológica de um momento crucial das trajetórias escolares. In: REUNIÃO ANUAL DA ASSOCIAÇÃO NACIONAL DE PÓS-GRADUAÇÃO E PESQUISA EM EDUCAÇÃO, 30., 2007, Caxambu: Anped, 2007. 30 anos de pesquisa e compromisso social.

OLIVEIRA, M. M. de. Como fazer pesquisa qualitativa. 4. ed. Petrópolis, RJ: Vozes, 2012.

PAULA, M. F. As políticas de democratização: do acesso ao ensino superior do governo Lula. Revista Advir, Rio de Janeiro, n. 23, p. 11-19, 2009.

PROGESTI. Missão da Progesti. Disponível em: < http://www.progesti.ufrpe. br/br/missao>. Acesso em: 10 out. 2017

PROGESTI. Relatório de Gestão Ano 2016. Disponível em: <http://www. progesti.ufrpe.br/br/dados_da_gestao>. Acesso em: outubro de 2017.

SARAVIA, E. Introdução à teoria da política pública. In: SARAVIA, E. E.; FERrAREZI, E. (Org.). Políticas públicas, coletânea. Brasília, DF: ENAP, 2007. v. 1, p. 21-42.

SGUISSARDI, V. Educação superior no Brasil. Democratização ou massificação no Brasil?. Educação e Sociedade. Campinas, v.36, n. 133, p. 867-899, 2015. 
SILVA JÚNIOR, J. R.; SGUISSARDI, V. A Educação superior privada no Brasil: novos traços de identidade. In: SGUISSARDI, V. (Org.). Educação superior: velhos e novos desafios. São Paulo: Xamã, 2000, p.155-180.

SOUZA, C. Políticas públicas: questões temáticas e de pesquisa. Caderno $\mathbf{C R H}$, Salvador, n. 39, p. 11-24, jul./dez. 2003.

VASCONCELOS, N. B. Programa de assistência estudantil: uma análise da evolução da assistência estudantil ao longo da história da educação superior no Brasil. 2009. Disponível em: <http://www.seer.ufu.br/index.php/emrevista/ article/download/.../6598>. Acesso em: 9 jul. 2017.

VASCONCELOS, I. C. O.; GOMES, C. A. Pedagogia dialógica para democratizar a educação superior. Ensaio: Avaliação e Políticas Públicas em Educação, v. 24, n. 92, p. 579-608, set. 2016.

JULIANA CAVALCANTI MACEDO possui Mestrado em Educação, Culturas e Identidades pela Universidade Federal Rural de Pernambuco (UFRPE) e Fundação Joaquim Nabuco (Fundaj). É pedagoga na Universidade Federal Rural de Pernambuco (UFRPE). Pesquisadora na área de políticas educacionais.

E-mail: julianacmacedo@gmail.com

ORCID: https://orcid.org/0000-0003-4111-2765

ANA DE FÁTIMA PEREIRA DE SOUSA ABRANCHES possui Mestrado e Doutorado em Educação pela Universidade Federal de Pernambuco (UFPE). É pesquisadora na Fundação Joaquim Nabuco (Fundaj) e professora no Programa de Pós-Graduação em Educação, Culturas e Identidades da Universidade Federal Rural de Pernambuco (UFRPE) e Fundação Joaquim Nabuco (Fundaj). Pesquisadora na área de políticas educacionais.

E-mail: anafpsa@gmail.com 